\title{
Alkaloids of the Ethnic Fruit Crop Khoonphal [Haematocarpus validus (Miers.) Bakh. f. ex Forman] from Andaman and Nicobar Islands
}

\author{
Blessymole K. Alex, Eapen P. Koshy ${ }^{*}$ and George Thomas
}

Department of Molecular and Cellular Engineering, JIBB, SHUATS, Allahabad, India

*Corresponding author

A B S T R A C T

\begin{tabular}{|l|}
\hline Ke y w o r d s \\
Haematocarpus \\
validus, Khoonphal, \\
HR LCMS, Alkaloids, \\
Nonvolatile \\
compounds.
\end{tabular}

Keywords

Haematocarpus HR LCMS, Alkaloids,

Nonvolatile

10 December 2017
Haematocarpus validus (Miers.) Bakh. f. ex Forman is a woody perennial climber belonging to the family of Menispermaceae and found in the hot and humid tropics of Asian continent. It is a lesser known and rare ethnic fruit crop of high nutraceutical and traditional medicinal value with hepatoprotective and anti-inflammatory properties. There is no report on the secondary metabolites present in this plant and this is the first report on various alkaloids present in the leaf and fruit samples of this ethnomedicinal plant. In the present communication, we report six alkaloid compounds viz., Ecgonine (leaf); Sinomenine (leaf); Metanephrine (fruit), Reticuline (fruit), Ambelline (fruit), and choline (in both leaf and fruit) detected through HR LCMS analysis.

\section{Introduction}

The 'moonseed family' Menispermaceae consists of 75 genera and around 520 species (Watson and Dallwitz, 1992); many of the members are traditionally used for therapeutic purposes. The family contains a wide range of benzylisoquinoline alkaloids and majority of these compounds are derived from the amino acid tyrosine. Haematocarpus validus is a member of the family Menispermaceae commonly known as 'Blood fruit' or 'koonphal' used in folklore medicine by ethnic groups of Meghalaya, Mizoram, Assam, Tripura, Andaman-Nicobar Islands (India), Bangladesh, Pakistan, Indonesia, Singapore and West Java. Fruits are rich in iron content and used for treating anaemic conditions (Singh et al., 2014; Rahim et al., 2015) and for blood purification (Momin et $a l ., 2016)$. The tender shoots and leaves are used for curing hepatic disorders, root extract to relieve itching and pain (Bohra et al., 2016). Even though this crop possesses immense nutritive and medicinal value, it occupies limited geographical locations and its potential uses are not yet explored. Furthermore, there are no scientific validation studies available to support the folklore knowledge on this underutilized fruit crop. In this context, it is necessary to unravel the metabolome of $H$. validus and the present investigation was designed to detect the nonvolatile compounds present in the methanolic 
fractions of the leaf and fruit extracts using HR LCMS analysis. This investigation provides information on alkaloid compounds of $H$. validus that support the traditional knowledge on the medicinal value of this plant.

\section{Materials and Methods}

Coarsely powdered leaf and fruit samples were extracted with methanol for the detection of compounds of non-volatile nature using HR LCMS facility provided by SAIF, IIT Bombay. HR LCMS was performed using 1290 Infinity UHPLC System of Agilent Technologies, USA (1260 infinity Nano HPLC with Chipcube, 6550 iFunnel QTOFs). The metabolites present in the methanolic extract were identified by comparing their retention indices (RI) and mass spectra fragmentation pattern with those on the stored library available in IIT, Bombay.

\section{Results and Discussion}

The present phytochemical analysis with the methanolic extract of leaf and fruit samples of Haematocarpus validus using HR LCMS detected three true heterocyclic isoquinoline alkaloids viz., sinomenine, (S)-reticuline, ambelline, one nonheterocyclic protoalkaloid metanephrin, one tropane group alkaloid ecgonine and one quaternary ammonium compound choline. The hetrocyclic isoquinolin alkaloids viz., sinomenine, (S)reticuline, and ambelline are derived from tyrosine. The protoalkaloid metanephrin is also the part of tyrosine metabolism. Out of the six compounds detected, choline was found in both leaf and fruit samples while ecgonine and sinomenine were detected in leaves; metanephrine, (S)-reticuline and ambelline were obtained from fruits (Table 1). The retention times (RT) and $\mathrm{m} / \mathrm{z}$ values recorded were as follows: choline (leaf- RT
4.544, m/z 104.1068; fruit- RT 4.557, m/z 104.1063), sinomenine (RT 13.822; m/z 330.1685), (S)-reticuline (RT 15.993, m/z 330.1684), ambelline (RT14.089; $\mathrm{m} / \mathrm{z}$ 314.1375), ecgonine (RT12.285; $\mathrm{m} / \mathrm{z} 168.1016)$. The fragmentation patterns of these compounds are presented in Figures 1-6. Details of these compounds are reported in the popular chemical databases of KEGG and PubChem. The KEGG id and Pubchem SID of the detected compounds are C00114, 3414 (choline); C09643, 11833 (sinomenine); C02105, 5187 ((S)-reticuline); C08517, 10710 (Ambelline); C10858, 13041 (ecgonine); C05588, 7913 (L Metanephrine) respectively.

The family Menispermaceae is rich in benzylisoquinoline alkaloids and many of them are used as medicinal drugs. The central intermediate in biosynthesis of these alkaloids are (S)-reticuline (Springob and Kutchan, 2009) and it was previously reported in many plants of Menispermaceae family (Dasgupta et al., 1979; Abbasoglu et al., 1991; Likhitwitayawuid et al., 1993; Nawai et al., 1999). (S)-reticuline is used in the preparation of drugs against cancer and malaria (Minami et al., 2008) and it also possesses cardiovascular effect (Medeiros et al., 2009).

Sinomenine (cocculin), an anti-rheumatic alkaloid reported earlier from Sinomenium acutum (Zhao et al., 2012) belonging to the same family, is detected in the leaf of $H$. validus. Ambelline is found generally in Amaryllidaceae plants that possess antimicrobial, anti-inflammatory, anti-cancer and antioxidant properties (Nair et al., 2012). Ecgonine is a tropane alkaloid and used as a mild vasodilator and topical anesthetic. Metanephrine is a protoalkaloid with rare occurrence in nature and assumed to have sympathomimetic properties. Previously Keller et al., (1973) isolated this compound from the cactus, Coryphantha macromeris. 
Table.1 Heterocyclic, non-heterocyclic and pseudoalkalod compounds detected in the leaf and fruit samples of $H$. validus

\begin{tabular}{|l|c|c|c|l|}
\hline Alkaloids & Formula & Class of compound & Found in & \multicolumn{1}{|c|}{ Biological significance } \\
\hline Choline & $\mathrm{C}_{5} \mathrm{H}_{14} \mathrm{NO}$ & $\begin{array}{c}\text { Quarternary } \\
\text { ammonium compound }\end{array}$ & $\mathrm{L}, \mathrm{F}$ & $\begin{array}{l}\text { Hepatoprotective activity (Zeisel } \\
\text { and da Costa, 2009; Idrus } \text { et al., } \\
\text { 2017) }\end{array}$ \\
\hline Ecgonine & $\mathrm{C}_{9} \mathrm{H}_{15} \mathrm{NO}_{3}$ & Tropane alkaloid & $\mathrm{L}$ & $\begin{array}{l}\text { Mild vasodilator (Hoffman } \text { et al., } \\
\text { 2004) }\end{array}$ \\
\hline Sinomenine & $\mathrm{C}_{19} \mathrm{H}_{23} \mathrm{NO}_{4}$ & Isoquinoline alkaloid & $\mathrm{L}$ & $\begin{array}{l}\text { Anti-inflammatory; anti rheumatic } \\
\text { alkaloid (Zhao } \text { et al., 2012) }\end{array}$ \\
\hline Metanephrine & $\mathrm{C}_{10} \mathrm{H}_{15} \mathrm{NO}_{3}$ & Protoalkaloid, & $\mathrm{F}$ & $\begin{array}{l}\text { Sympathomimetic properties } \\
\text { (Keller } \text { et al., 1973) }\end{array}$ \\
\hline (S)-Reticuline & $\mathrm{C}_{19} \mathrm{H}_{23} \mathrm{NO}_{4}$ & Isoquinoline alkaloid & $\mathrm{F}$ & $\begin{array}{l}\text { Cardiovascular effect (Medeiros } \text { et } \\
\text { al., 2009). }\end{array}$ \\
\hline Ambelline & $\mathrm{C}_{18} \mathrm{H}_{21} \mathrm{NO}_{5}$ & Isoquinoline alkaloid & $\mathrm{F}$ & $\begin{array}{l}\text { Antimicrobial, anti-inflammatory, } \\
\text { anticancer and antioxidant } \\
\text { properties (Nair } \text { et al., 2012) }\end{array}$ \\
\hline
\end{tabular}

L - Leaf sample; F - Fruit sample

Fig.1 Choline from fruit sample

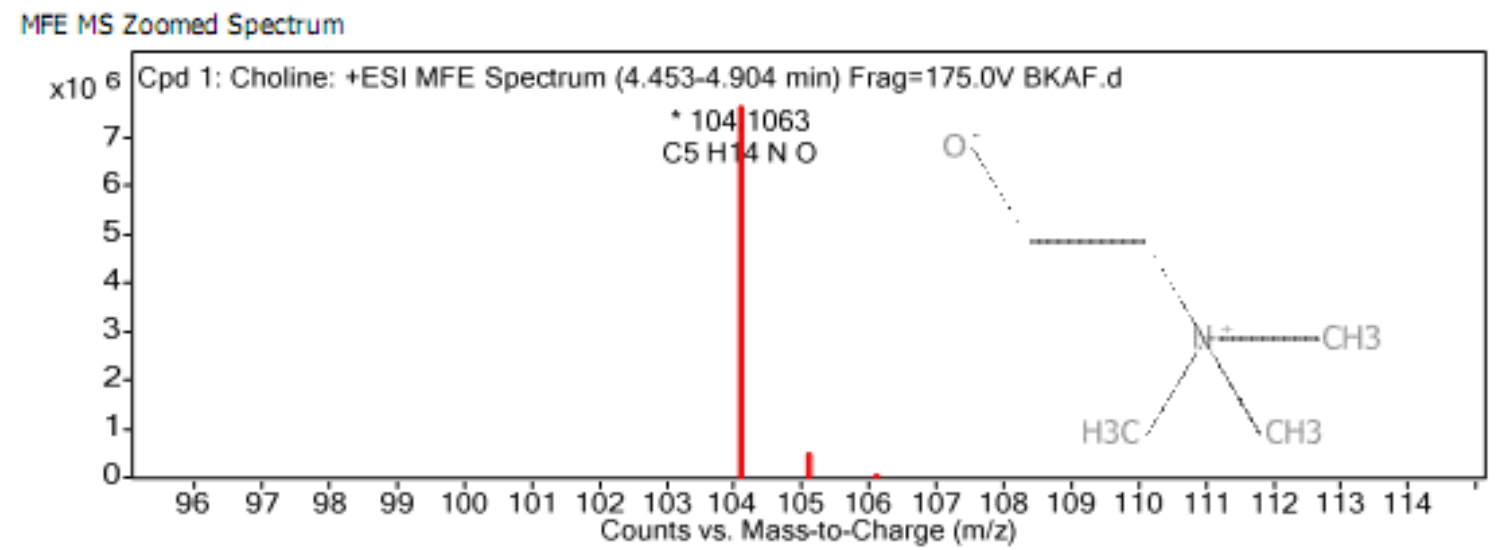

Fig.2 Ecgonine from leaf sample

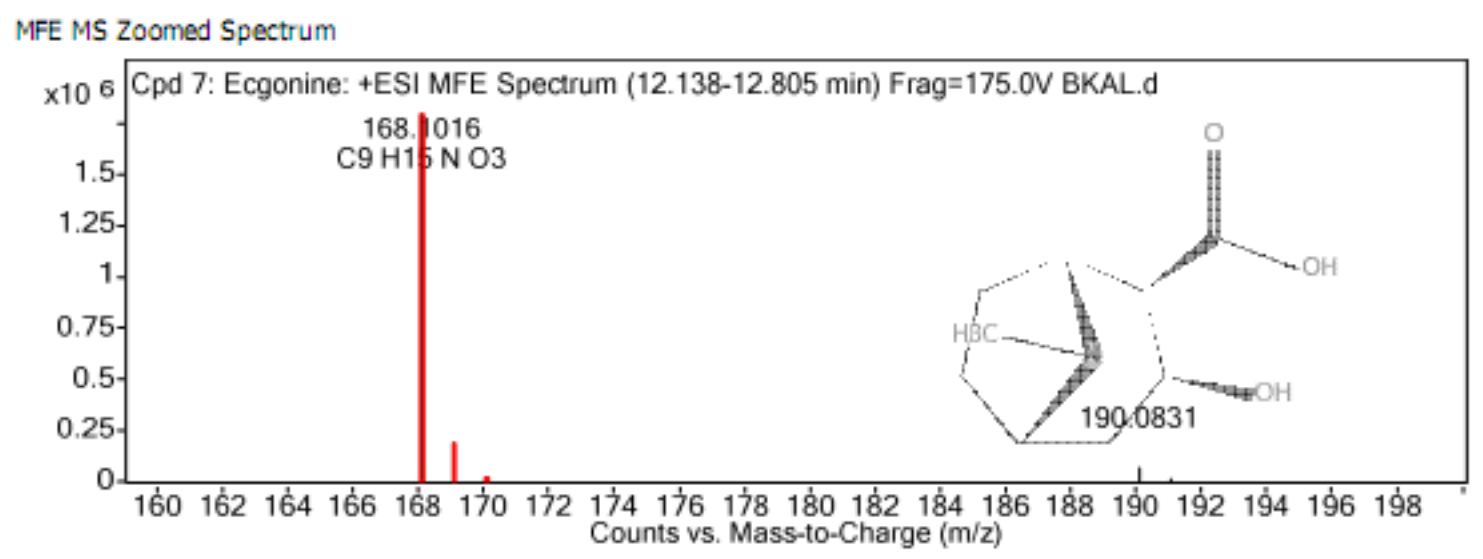


Fig.3 Sinomenine from leaf sample

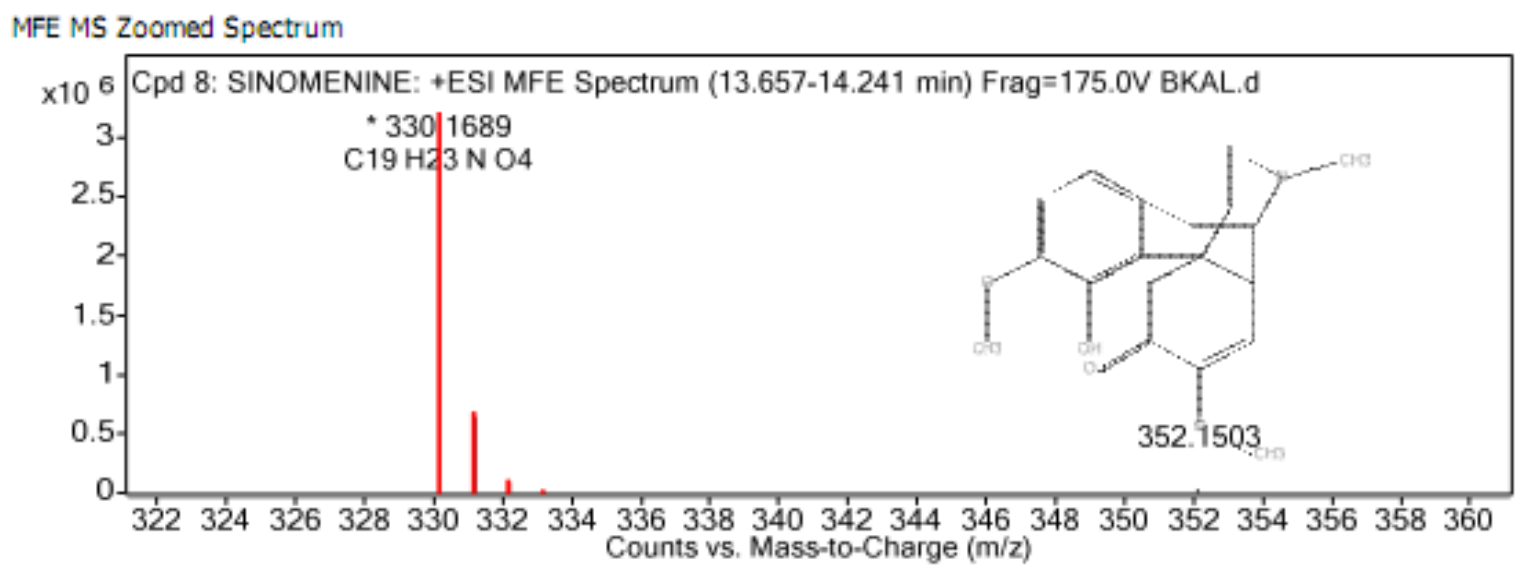

Fig.4 Metanephrine from fruit sample

MFE MS Zoomed Spectrum

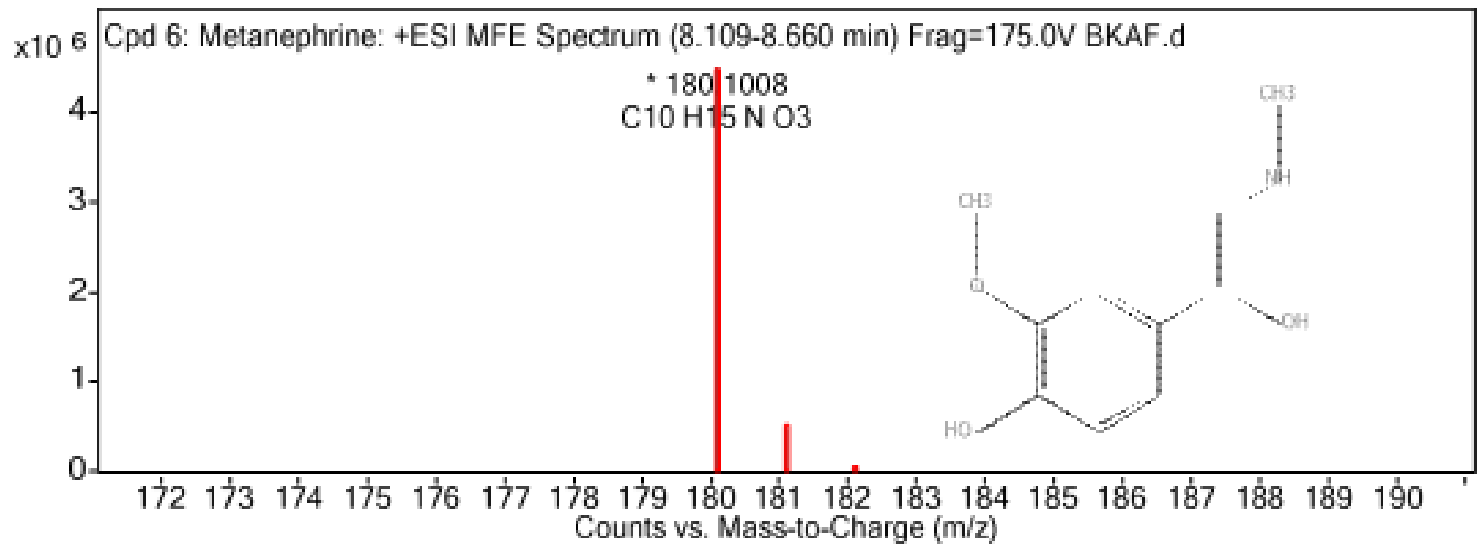

Fig.5 (S)-Reticuline from fruit sample

MFE MS Zoomed Spectrum

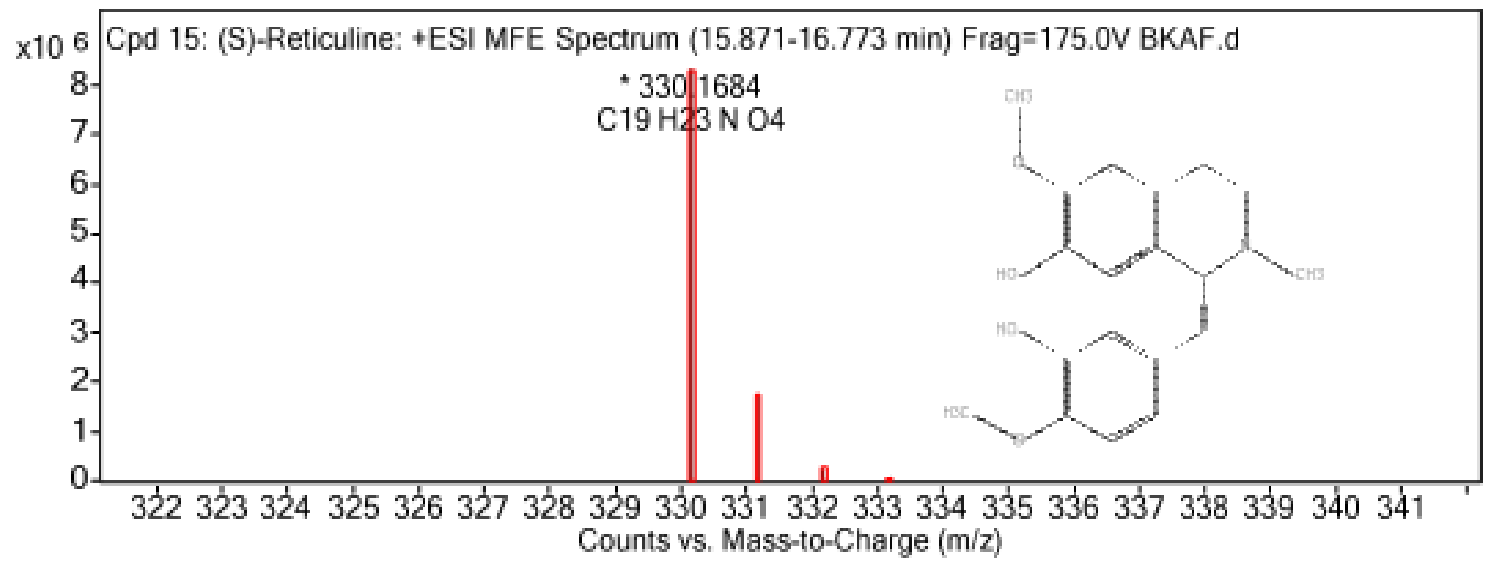


Fig.6 Ambelline from fruit sample

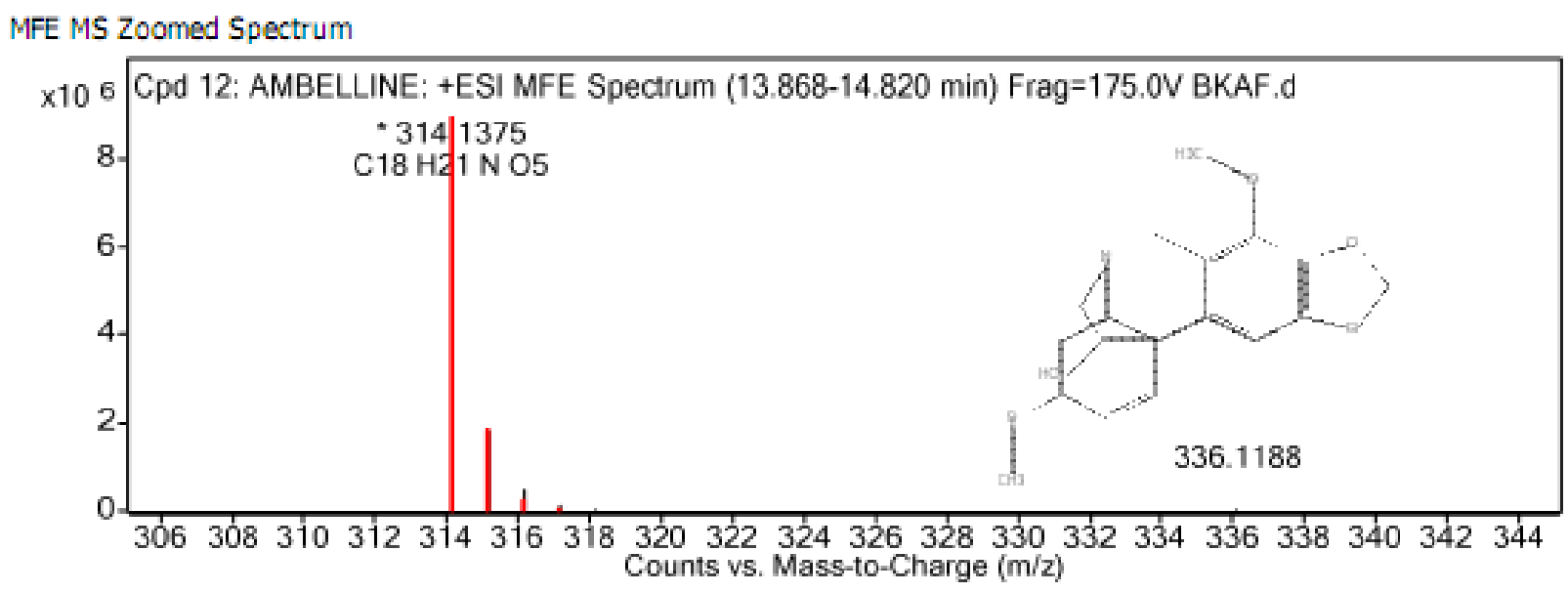

Choline is a quaternary ammonium compound with nutritional importance and used for liver health (Zeisel, 1992; Zeisel and da Costa, 2009; Idrus et al., 2017) and it was reported previously from Menispermaceae plants including Tinospora cordifolia.

In conclusion, the current HR LCMS analysis of the lesser known medicinally important fruit crop Haematocarpus validus revealed the presence of six alkaloid compounds in the methanolic fractions of leaf and fruit extracts.

The detected alkaloid compounds include Sinomenine, (S)-Reticuline, Ambelline, Metanephrine, Ecgonine and Choline show biological significance in terms of hepatoprotective, anti-inflammatory, antirheumatic, cardiovascular, antimicrobial, anticancer and antioxidant properties.

The therapeutic potential of these alkaloid compounds support the folklore knowledge regarding this ethnomedicinal plant. Considering the enormous medicinal prospects as well as its rare and vulnerable status, this crop needs conservation, domestication and propagation in the humid and hot tropics of Asian continent for its better utilization.

\section{References}

Abbasoglu, U., Sener, B., Gunay, Y. and Temizer, H. 1991. Antimicrobial activity of some isoquinoline alkaloids. Archiv der Pharmazie. 324:379-380.

Bohra, P., Waman, A.A. and Roy, S.D. 2016. Khoon phal (Haematocarpus validus (Miers.) Bakh.Ex F. Forman). CRPAB/Underutilized Species/T.B.-01, ICARCIARI, Port Blair. pp. 1-8.

Dasgupta, S., Ray, A.B., Bhattacharya, S.K. and Ray, R. 1979. Constituents of Pachygone ovate and pharmacological action of its major leaf alkaloids. Journal of Natural Products. 42:1-85.

Hoffman, R.S., Kaplan, J.L., Hung, O.L. and Goldfrank, L.R. 2004. Ecgonine methyl ester protects against cocaine lethality in mice. Journal of Toxicology. 42(4):349354.

Idrus, N.M., Breit, K.R. and Thomas, J.D. 2017. Dietary Choline levels modify the effects of prenatal alcohol exposure in rats. Neurotoxicology and Teratology. 59:43-52.

Keller, W.J., McLaughlin, J.L. and Brady, L.R. 1973. Cactus alkaloids XV: $\beta$ Phenethylamine derivatives from Coryphantha macromeris var. runyonii. Journal of Pharmaceutical Sciences. 62(3):408-411.

Likhitwitayawuid, K., Angerhofer, C.K., Chai, H., Pezzuto, J.M., Cordell, G.A. and 
Ruangrungsi, N. 1993. Traditional medicinal plants of Thailand. XXIII. Cytotoxic and antimalarial alkaloids from the tubers of Stephania pierrei. Journal of Natural Products. 56:1468-1478.

Medeiros, M.A.A., Nunes, X.P., BArbosa-Filho, J.M., Lemos, V.S., Pinho, J.F., RomanCampos, D., deMedeiros, I.A., Araujo, D.A.M. and Cruz, J.S. 2009. (S)-reticuline induces vasorelaxation through the blockade of L-type $\mathrm{Ca}^{2+}$ channels. NaunynSchmiedeberg's Archives of Pharmacology. 379(2):115-125.

Minami, H., Kim, J.S., Ikezawa, N., Takemura, T., Katayama, T., Kumagai, H. and Sato, F. 2008. Microbial production of plant benzylisoqinoline alkaloids. Proceedings of the National Academy of Sciences, USA. 105(21):7393-7398.

Momin, K. C., Suresh, C. P., Momin, B. C., Singh, Y. S. and Singh, S. K. 2016. An ethno-botanical study of wild plants in Garo Hills region of Meghalaya and their usage. International Journal of Minor Fruits, Medicinal and Aromatic Plants. 2(1):47-53.

Nair, J.J., Bastida, J., Viladomat, F. and van Staden, J. 2012. Cytotoxic agents of the crinane series of Amaryllidaceae alkaloids. Natural Product Communications. 7(12):1677-1688

Nawai, S., Ma, C., Nakamura, N., Hattori, M., Kurokawa, M., Shiraki, K., Kashiwaba, N. and Ono, M. 1999. Anti-herpes simplex virus activity of alkaloids isolated from Stephania cepharantha. Biological and Pharmaceutical Bulletin. 22(3):268-274.

Rahim, M.A., Khatun, M.J.M., Rahman, M.M., Anwar, M.M. and Mirdah, M.H. 2015.
Study on the morphology and nutritional status of Roktogota (Haematocarpus validus) - an important medicinal fruit plant of hilly areas of Bangladesh. International Journal of Minor Fruits, Medicinal and Aromatic Plants. 1:11-19.

Singh, D.R., Singh, S. and Banu, V.S. 2014. Estimation of phytochemicals and determination of betacarotene in Haematocarpus validus an underutilized fruit of Andaman and Nicobar Islands. European Journal of Environmental Ecology. 1:12-15.

Springob, K. and Kutchan, T.M. 2009. Introduction to different classes of Natural Products. In: Osbourn, A.E. and Lanzotti, V. (eds.) Plant derived Natural Products: Synthesis, Function and Application. Springer. pp.3-50.

Watson, L. and Dallwitz, M.J. 1992. The families of flowering plants: Descriptions, Illustrations, Identification and Information Retrival. Available at http://biodiversity. uno.edu/delta/angio/www/menisper.htm.

Zeisel, S.H. 1992. Choline: an important nutrient in brain development, liver function and carcinogenesis. Journal of the American College of Nutrition. 11(5):473-481.

Zeisel, S.H. and da Costa, K.A. 2009. Choline: an essential nutrient for public health. Nutrition Reviews. 67(11):615-623.

Zhao, X.X., Peng, C., Zhang, H. and Qin, L.P. 2012. Sinomenium acutum: a review of chemistry, pharmacology, pharmaco kinetics and clinical use. Pharmaceutical Biology. 50:1053-1061.

\section{How to cite this article:}

Blessymole K. Alex, Eapen P. Koshy and George Thomas. 2017. Alkaloids of the Ethnic Fruit Crop Khoonphal [Haematocarpus validus (Miers.) Bakh. f. ex Forman] from Andaman and Nicobar Islands. Int.J.Curr.Microbiol.App.Sci. 6(12): 2797-2802. doi: https://doi.org/10.20546/ijcmas.2017.612.324 